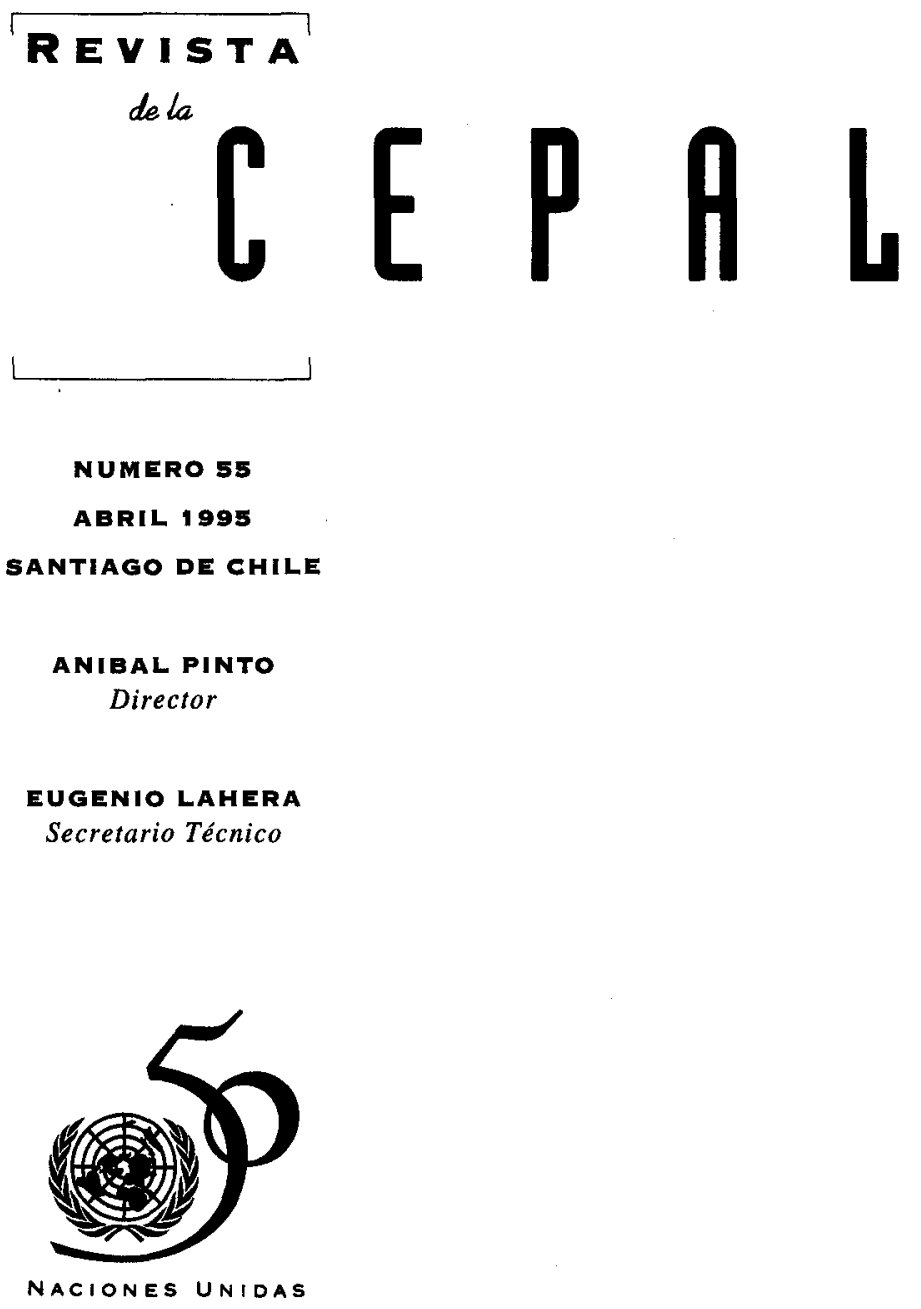


Una síntesis de la propuesta de la CEPAL

Eugenio Lahera, Ernesto Ottone y Osvaldo Rosales

Consolidación de la paz después de los conflictos:

un desafío para las Naciones Unidas

Graciana del Castillo

Descentralización y democracia: el nuevo municipio latinoamericano

Eduardo Palma

Economía política del proteccionismo después de la Ronda Uruguay

José Tavares

Política comercial e inserción internacional.

Una perspectiva latinoamericana

Marta Bekerman y Pablo Sirlin

Movimientos de capital y financiamiento externo

Benjamín Hopenhayn

Impacto de la política cambiaria y comercial sobre el desempeño

exportador en los años ochenta

Graciela Moguillansky

Situación y perspectivas ambientales en América Latina y el Caribe

Nicolo Gligo

Expectativas de la juventud y el desarrollo rural

Martine Dirven

Empresas transnacionales y cambios estructurales en la industria de Argentina, Brasil, Chile y México

Ricardo Bielschowsky y Giovanni Stumpo

El Salvador: política industrial, comportamiento empresarial y perspectivas

Roberto Salazar

El cambio tecnológico en los análisis estructuralistas

Armando Kuri

Orientaciones para los colaboradores de la Revista de la CEPAL 


\section{Movimientos de capital y financiamiento externo}

\section{Benjamín Hopenhayn}

Instituto de Investigaciones Económicas, Facultad de

Ciencias Económicas,

Universidad de Buenos Aires.
En este artículo se exploran las causas, consecuencias, magnitud y formas de un fenómeno fundamental del escenario contemporáneo y de enorme incidencia en las economías latinoamericanas: la aceleración de los movimientos internacionales de capital. Billones de dólares se transan por satélite a través de las fronteras, y una pequeña fracción de ellos se ha constituido en el elemento básico del financiamiento externo de América Latina. Esta globalización financiera enraiza en la acumulación de enormes excedentes líquidos vinculados, la liberalización generalizada de las cuentas de capital tras el derrumbe de las fronteras de Bretton Woods y el impacto de la revolución tecnológica de la informática y las comunicaciones. La creciente dimensión de los mercados financieros y los desequilibrios externos de los principales países requieren un nuevo régimen monetario internacional, todavía indefinido, pero con libre circulación de grandes masas líquidas que toman formas cada vez más diversas: son los productos financieros que se mueven en los mercados transnacionales del dinero. En los últimos años, ellos han contribuido a aliviar el sector externo de América Latina y a complementar su ahorro interno. Pero lo impredecible y riesgoso de esas corrientes de capital aconsejan aprovechar la bonanza para realizar transformaciones que aumenten el ahorro nacional y lo apliquen a elevar la productividad y la competitividad de las economías de la región. 


\section{El movimiento de capitales}

\section{a través de las fronteras}

En las últimas décadas el movimiento de capitales a través de las fronteras ha crecido a la velocidad vertiginosa de los satélites que los transportan. Son cientos de miles de millones de dólares por día, de billones (trillones estadounidenses) por año, que el lenguaje electrónico registra como asientos de compra y venta de activos financieros cada vez más diversos. Son, como gustan llamarlos los operadores, "productos" financieros. Y como ocurre en el mundo del comercio de bienes físicos, esos productos se hacen cada vez más diferenciados para mantener la competitividad de los "productores" en los mercados del dinero.

A pesar del vértigo que su magnitud y la abstracta diversidad de sus formas puedan producirnos, debemos hacer todo lo posible por comprender las causas y las consecuencias, la magnitud y las formas de este fenómeno fundamental del funcionamiento de la economía contemporánea.

Empecemos con un poco de historia. ¿Cómo se ha llegado a la gran movilidad internacional de capitales que sustenta la creciente tendencia a la llamada globalización financiera? Veremos que las causas principales son la acumulación de grandes excedentes líquidos, la liberación generalizada de los controles de capital y el impacto de la revolución tecnológica de la informática y las comunicaciones. Este proceso llevó a un grupo de distinguidos economistas franceses de la escuela regulacionista -intervencionista, dirían los neoconservadores criollos - a calificar la globalización financiera como "la aventura obligada" (Aglietta y otros, 1990). Aventura que mueve a agentes privados y públicos a tomar recaudos para aprovechar sus ventajas y esquivar sus peligros, compitiendo en el corto plazo por retornos elevados y oportunidades de ingreso.

La historia contemporánea de los movimientos internacionales de capital y su relación con el financiamiento de los desequilibrios de balance de pagos comienza con la Conferencia de Bretton Woods, antes de finalizar la segunda guerra mundial. De paso recordemos que hace pocos meses se cumplió el cincuentenario de esa trascendental conferencia, curiosamente sin mayores festejos.

Los acuerdos de Bretton Woods pretendían sen- tar para la posguerra las bases de un régimen de relaciones económicas internacionales eficaz para el desarrollo de la economía mundial. Los personajes que se sentaron con poder real de negociación a la mesa de Bretton Woods recordaban vivamente dos experiencias traumáticas de la primera mitad del siglo. Por un lado, la devastadora crisis causada por la literal explosión de una enorme burbuja financiera y su veloz transmisión de un país a otro por falta, entre otras cosas, de una salvaguardia monetaria internacional ordenada. Y por otro, las desastrosas consecuencias políticas y económicas de las reparaciones de guerra impuestas a los vencidos. Para salvar ambas vallas se crearon el Fondo Monetario Internacional (FMI) y el Banco Internacional de Reconstrucción y Fomento (Banco Mundial). No llegó a crearse - por la oposición del Senado estadounidense - la tercera pata del trípode, es decir, una organización mundial del comercio (posteriormente remedada por el GATT y revivida con otros rasgos en la Ronda Uruguay).

El organismo más novedoso e importante surgido de Bretton Woods fue sin duda el Fondo Monetario Internacional. El Acuerdo, o artículos de acuerdo constitutivo del Fondo, establecía entre sus principales objetivos el de contribuir a la vigencia de condiciones propicias para el pleno empleo, mediante el crecimiento no inflacionario de la economía y el comercio mundiales, apoyado en un sistema multilateral de pagos internacionales y fuertes restricciones a la libertad de cambios. (El Banco Mundial aportaría recursos para la reconstrucción de los países devastados por la guerra, especialmente de Europa, sin distinción de vencidos y vencedores, en paralelo con el Plan Marshall).

La relación de poder prevaleciente al final de la guerra y las reglas del juego establecidas en Bretton Woods, construyeron de hecho y de derecho un sistema monetario internacional hegemónico. Hegemónico porque en ese sistema la economía de los Estados Unidos funcionaba como "locomotora" de la mitad capitalista del mundo y el dólar como unidad monetaria internacional de cambio y de reserva.

Es un hecho que el mundo conoció en el cuarto de siglo posterior a la segunda guerra mundial el pe- 
ríodo más prolongado de crecimiento con estabilidad que recuerda la historia moderna. Ilustran la evolución económica de ese cuarto de siglo una tasa media de crecimiento del producto cercana al 5\% acumulativo anual, con una expansión del comercio internacional del orden del $8 \%$ y tasas de inflación inferiores al $2-3 \%$ por año, y con ciclos suavizados por políticas de inspiración keynesiana. Condiciones que, como sabemos por las lecciones de la realidad y de su interpretación por Raúl Prebisch, prevalecieron en el mundo de los países industrializados del centro, y se derramaron muy mezquinamente a los países subdesarrollados de la periferia.

De todos modos, esas tasas de crecimiento permitieron la acumulación de recursos físicos y financieros formidables que cambiaron la fisonomía de las economías de mercado centrales (anotemos de paso que también los países socialistas parecieron crecer notablemente en ese cuarto de siglo). Junto con la producción y el comercio, crecía la acumulación de excedentes financieros y se desarrollaban los mercados de capital, tanto nacionales - de los países centrales, por supuesto- como internacionales.

Pero a medida que aumentaba la dimensión de los mercados financieros crecían las tensiones sobre diversos eslabones de los sistemas que los regulaban. $\mathrm{Y}$ un eslabón que paradójicamente se iba debilitando era el propio dólar, sobre el cual se asentaba todo el régimen concertado en Bretton Woods.

Sobre este proceso de debilitamiento sistémico y los peligros que entrañaba cabe reconocer dos advertencias importantes de economistas maduros y visionarios. La primera fue la propuesta que había hecho Keynes en la Conferencia de Bretton Woods, de anclar el sistema en un medio internacional de pago no nacional, el bancor, anclado a su vez en el oro, que se transaría entre gobiernos a través de una unión de pagos o caja de compensaciones internacional. Como se sabe, en Bretton Woods esta propuesta no fue aceptada. Se adoptó en cambio el plan de White - representante de los Estados Unidos- de crear un fondo internacional de estabilización con divisas y oro aportados por sus miembros. Este fondo concedería créditos de corto plazo a los países que tuvieran déficit coyunturales de pagos, a cambio de compromisos generales de converger hacia la convertibilidad monetaria y la libertad de comercio, y compromisos más específicos de no devaluar salvo en "circunstancias excepcionales y estructurales", y con el acuerdo previo del fondo.

Una digresión keynesiana. Algún economista contemporáneo (Davidson, 1991, pp. 85-104) recor- dó que en 1941 —año de la Carta del AtlánticoKeynes había escrito: "Suponer que existe algún mecanismo automático de funcionamiento normal de ajuste que preserve el equilibrio si sólo confiamos en los métodos del laissez faire es una ilusión doctrinaria que desatiende las lecciones de la experiencia histórica sin tener detrás el apoyo de una teoría firme".

$\mathrm{El}$ régimen monetario internacional que se estableció finalmente, de hecho tuvo como moneda central el dólar, anclado a un determinado peso en oro, y con el tipo de cambio de todas las otras monedas fijado a su paridad con el dólar. Esto permitía tener durante un largo período un sistema hegemónico y, por lo tanto, estable. Hegemónico porque estaba organizado sobre la base de un solo país, con los privilegios (entre ellos el de "señoreaje") y las responsabilidades de líder y centro del sistema. Estable mientras se mantuviera el ancla de una economía fuerte, dinámica y con responsabilidad en el ejercicio de una política monetaria prudente y anticíclica.

Vale la pena recordar que también se acordó en Bretton Woods que se permitiría mantener restricciones a la movilidad de capitales, por temor a los desequilibrios que éstos podrían causar. Veremos que con el tiempo estas restricciones fueron siendo levantadas por los gobiernos o simplemente superadas por los "mercados". Pero no nos adelantemos.

La segunda advertencia fue la visionaria percepción de Robert Triffin, quien desde comienzos de los años sesenta anunció que el régimen establecido desembocaría inevitablemente en una crisis, pues el patrón dólar se vería ante un dilema parecido al que había enfrentado la libra en su período hegemónico: i) inflación interna (por emisión monetaria excesiva para responder a la demanda del resto del mundo), la que se transmitiría internacionalmente, o bien ii) deflación para evitar un déficit de pagos por un mecanismo similar al patrón oro, la que también se transmitiría internacionalmente, con el peligro de desencadenar una crisis de depreciaciones competitivas como las de traumáticos episodios anteriores.

Esta advertencia de Triffin, ampliamente escuchada en los círculos académicos influyentes en el Gobierno de Estados Unidos de entonces, coincidió a poco andar con otros fenómenos del mundo real. Por una parte, desde la Europa reconstruida y encaminada hacia la unión se presionaba para que se superara la hegemonía del dólar (de la cual las transnacionales estadounidenses usufructuaban). Cabe recordar las reclamaciones de De Gaulle pidiendo el retorno a la disciplina neutral del patrón oro, cuando ya Europa 
crecía a todo vapor y descendía notoriamente la participación de Estados Unidos en el producto económico y en el comercio internacional, a pesar de seguir siendo la economía más poderosa del mundo.

Por otra parte, desde comienzos de los años sesenta venían surgiendo mercados financieros extraterritoriales, que ofrecían no sólo paraísos fiscales, sino también paraísos de capital anónimo, desregulados y sin control de autoridades monetarias nacionales.

Entre éstos mercados financieros comenzaron a destacarse los que se llamarían "euromercados". La leyenda cuenta que éstos nacieron en Londres del ingenio de banqueros de la City, para "lavar" divisas soviéticas. Estos mercados, que por la reputación británica brindaban garantías de seriedad y buen manejo, tentaron a capitales financieros de otros países, porque ofrecían un mayor interés y porque no exigían identificación ni aplicaban regulación de pasivos y activos.

La tasa más favorable que representaba la LIBOR, el secreto del manejo de fondos y la desregulación, aparte de las ventajas impositivas, empezaron a atraer a los euromercados fondos provenientes de muchos orígenes y lugares, de inversores y de intermediarios financieros. Entre ellos, de los grandes bancos estadounidenses. Para el gobierno de los Estados Unidos esto era una incipiente fuga de capitales. A partir de allí, desde mediados de los años sesenta, comenzó un período poco recordado, una suerte de ensayo de la oleada que se vendría después. Los grandes bancos - el mercado - procuraban extender sus fronteras a través de la porosidad fronteriza y de sus sucursales en Londres. El gobierno de los Estados Unidos pugnaba por disciplinar esos mismos movimientos, de difícil registro y supervisión.

El resultado de estas tensiones $-\mathrm{y}$ de los cambios que ocurrían en la esfera de la producción y del comercio- llevó a presiones devaluatorias -especulativas en buena parte-contra el dólar en relación con las monedas fuertes de Europa. Como se sabe, finalmente se llegó a la decisión de suprimir la convertibilidad del dólar a oro - obligación contraída por Estados Unidos en los tratados de Bretton Woods-y de devaluar la moneda central del sistema. Tampoco estas medidas tan importantes satisficieron a los mercados, ya que finalmente hubo que derribar el mismo muro a las devaluaciones competitivas que se había erigido en Bretton Woods, y se pasó de una época de paridades fijas o semifijas a otra de paridades o tipos de cambio flexibles, que la historia de los dos decenios siguientes mostraría de una enorme volatilidad cambiaria.

En efecto, derribado el muro de las paridades fijas y del propio tratado de Bretton Woods al alborear los años setenta, el vacío de un nuevo orden fue fundamental para que la crisis de los precios del petróleo tuviera un efecto tan deletéreo sobre la economía mundial. Se abrió entonces un largo ciclo de grandes desequilibrios externos, de estancamiento con inflación en los países centrales, que se extendió hasta comienzos de los años ochenta.

Los países centrales comenzaron a recuperar el equilibrio de sus economías después de una recesión aguda y empezó a abatirse la inflación, pero el ritmo de crecimiento era mucho más lento que en la dorada era de la posguerra. Tampoco la estabilidad era tan estable, como se manifiesta, entre otros indicadores, por la volatilidad de las paridades cambiarias y de las tasas de interés de influencia internacional. $Y$ en cuanto a aquel lejano objetivo del pleno empleo, que figuraba al inicio de los estatutos del Fondo pareció haber perdido la batalla ante la plena vigencia aparente de la curva de Philips: un elevado desempleo "natural" coincidió con la respuesta "monetarista" a la inflación.

Hoy el nivel de desempleo es una de las preocupaciones centrales de los propios países desarrollados. Tanto así que en el último informe del Fondo sobre las perspectivas de la economía mundial (FMI, 1994) el propio FMI se pregunta si es reversible el aumento del desempleo, porque considera que el "costo económico y los costos sociales de los actuales niveles de desempleo, ya sea estructural o cíclico, son enormes" (Ibíd. p. 39). A nuestro parecer el problema contemporáneo del desempleo es de raíz más bien estructural y microeconómica o tecnológica, y no habrá manera de resolverlo —ni allá ni acá- con políticas de la vertiente monetarista, ni siquiera con atinadas correcciones fiscalistas. Pero este es otro tema.

La perspectiva de los años setenta y ochenta desde nuestro destino - latinoamericano y argentino- esclarece el origen y el desenlace de la crisis de la deuda. En efecto, a partir de 1973 sobre ese continente de paridades variables y volátiles y de mercados financieros libres de regulación y vigilancia - los euromercados, hoy extraterritoriales - se vuelcan los enormes excedentes provocados por el shock de los precios del petróleo, que acumuló superávit fabulosos en países con muy poca capacidad de absorberlos. Los petrodólares multiplicaron así las corrientes líquidas internacionales, en un período en que los países centrales atravesaban largos años de estancamiento con inflación. Sobra la liquidez, y amenaza la estabilidad mundial.

En este período, los bancos internacionales —elogiados por el Fondo en sus informes oficiales 
y por la prensa económica internacional- contribuyen a resolver el difícil problema del reciclaje de los petrodólares en forma de préstamos fáciles y baratos que, entre otras cosas, sobreendeudan a casi todos los países de América Latina. Por supuesto que no todo viene por el lado de la oferta, y que una demanda alegre e irresponsable contribuye al sobreendeudamiento.

En esta perspectiva latinoamericana, la crisis de la deuda tiene sus raíces en el gran desorden del régimen monetario internacional de los años setenta, tanto como en la ligereza o irresponsabilidad de algunos prestatarios. Es éste el fondo del problema de la asimetría en el tratamiento de la deuda, superado en los hechos con la década perdida y la limpieza de los balances de los grandes bancos transnacionales. Tema que como veremos nos interesa, porque así como en la segunda mitad de los años setenta abundaron los capitales externos para América Latina, en estos primeros años de los noventa abundan también los capitales externos, aunque vengan en forma distinta. Y esto último puede ser muy importante, por lo cual es tan aventurado hacer analogías como imprudente no hacerlas.

Resumamos. En las dos décadas de gran crecimiento de la economía mundial se acumularon cuantiosos excedentes financieros. Se fortalecieron los mercados de capitales, junto con los otros mercados. Surgieron mercados financieros internacionales libres de regulación y control. Se debilitaron primero y se derrumbaron después los muros de control establecidos en Bretton Woods para mantener un cierto orden monetario internacional regulado. Los desequilibrios de pagos o cuentas corrientes se acentuaron y tomaron la forma de shock con la multiplicación de los precios del petróleo. Coincidieron así importantes cambios institucionales en los mercados financieros internacionales con masas cada vez mayores de recursos líquidos para intermediar. Al mismo tiempo la econo- mía mundial entró en un período de alta volatilidad de los dos precios principales del dinero internacional: las tasas de interés y los tipos de cambio.

Para que este explosivo aumento de los fondos de circulación internacional cada vez más libre llegara a constituir una verdadera revolución sólo faltaba un ingrediente tecnológico. Este apareció simultáneamente con el gran salto de la informática y las comunicaciones. Esos fondos pudieron ya circular globalmente en su forma más abstracta - casi sin metales, sin dinero, sin papeles-y en tiempo real a través de los satélites que unen los mercados financieros del mundo en días de 24 horas.

Junto con todos los fenómenos anteriores se fue produciendo en el mundo una gradual desregulación de las cuentas de capital que controlaban los movimientos de divisas a través de las fronteras. No fue éste un movimiento instantáneo y masivo. Recordemos que varios países importantes - como Francia, Japón, y otros - liberaron sus cuentas de capital hace apenas un lustro. Pero ya hoy la liberalización de los movimientos de capitales es prácticamente completa, por lo menos en las economías de mercado.

Concluyamos aquí esta rápida revisión de los sucesos que llevan al régimen monetario y financiero internacional de nuestros días. Este régimen, todavía en conformación, es cierto, se basa crecientemente en la libertad de los mercados de divisas, con flotación cada vez más débilmente administrada. Es que resulta difícil aplicar límites de prudencia en un gran mercado donde hay actores privados tan poderosos que tuercen a menudo el brazo de los bancos centrales más sólidos. Esos capitales se mueven en gran parte a través de los bancos y en sociedad con los mismos - apalancamiento-, y la diversificación de sus instrumentos los mantiene fuera del alcance de las autoridades monetarias nacionales, como lo muestra la evolución de los convenios de supervisión bancaria del Comité de Basilea. ${ }^{1}$

\section{II}

\section{Formas y dimensión de los movimientos. internacionales de capital}

Tratemos ahora de caracterizar a grandes rasgos las formas y la dimensión de los movimientos internacionales de capital, antes de abordar las consecuencias sistémicas de su liberalización y expansión en el mundo contemporáneo.
Lo que primero llama la atención al estudiar la evolución de estos mercados es que en un par de décadas el movimiento de capitales a través de las

1 Sobre este tema véase Cornford, 1993. 
fronteras se extiende crecientemente más allá del comercio internacional, de las inversiones extranjeras directas y de los tradicionales depósitos y préstamos bancarios. Los mercados de capitales, nacionales e internacionales, abarcan una gama vasta y creciente de activos financieros. Analíticamente éstos pueden dividirse en cinco grandes grupos: operaciones ligadas al comercio, inversiones extranjeras directas, préstamos bancarios, inversiones de cartera, y otros.

Por supuesto que las operaciones ligadas al financiamiento del comercio internacional siguen la evolución del intercambio de bienes y servicios, que en estos últimos años creció lentamente, poco más que la producción mundial. Las inversiones extranjeras directas, que en los años ochenta se concentraron entre países del Norte, en estos últimos años aumentaron en algunos países en desarrollo, tanto del Asia como de América Latina. En Argentina, como es sabido, la inversión extranjera directa de tiempos recientes ha estado muy ligada a las privatizaciones.

También crecieron en los últimos años las colocaciones de bonos y títulos con respaldo soberano o de activos más o menos "titularizados"; las inversiones de cartera en acciones $u$ otras obligaciones de alta liquidez, y los movimientos especulativos de entrada y salida desarraigados de cualquier operación vinculada a la producción, la inversión o el comercio.

Impresiona la proliferación de "productos financieros", especialmente de futuros, opciones y toda suerte de derivados. La lista de ellos -el menú- es larga y abierta. Una sofisticada ingeniería financiera aprovecha los cambios institucionales y tecnológicos. La competitividad hace medir a los operadores con la vara del ingenio innovador para multiplicar los "productos" que se transan en los mercados de las finanzas internacionales.

La medición de los flujos internacionales de capital presenta problemas muy complejos, que se manifiestan en la conocida discrepancia estadística de los balances de pagos que registra y publica el Fondo Monetario Internacional. Esa discrepancia refleja un acervo creciente de activos financieros externos reconocidos por los países que los emiten, pero que no aparecen en las estadísticas de los países cuyos residentes los adquieren. Para tener una idea del volumen de recursos que escapa al registro y medición: en la última década la discrepancia estadística promedió los 50000 millones de dólares por año.

Las dificultades de medición y conciliación de las cuentas de capital llevaron al Directorio del Fondo a crear un grupo de trabajo, presidido por el Barón
Godeaux, para evaluar las prácticas estadísticas relacionadas con la medición de las corrientes internacionales de capital y en particular las fuentes principales de la discrepancia estadística. El informe presentado por ese grupo destacaba que la liberalización de los mercados de capital, las innovaciones financieras y los cambios en las preferencias de los inversionistas han hecho muy difícil medir las inversiones de cartera; que no se cuenta con información completa de los centros financieros extraterritoriales, y que se ocultan importantes corrientes asociadas con el tráfico de narcóticos y de armas.

Estas advertencias no sólo aconsejan cautela ante la confiabilidad de esos datos, aunque sean los únicos que tengamos. También ilustran sobre las dificultades que enfrentan los gobiernos para supervisar los movimientos del capital a través de las fronteras del mundo.

A pesar de las dificultades de medición, hay datos que permiten ilustrar las dimensiones de las corrientes internacionales de capital. Comencemos con los movimientos más convencionales: los del crédito bancario privado. En los años ochenta el total mundial de los préstamos bancarios extrafronterizos creció $280 \%$, superando ya los 8 billones (trillones estadounidenses) de dólares. Durante ese lapso los activos totales de los bancos estadounidenses se duplicaron, y los del Japón se triplicaron. Para comparar, recordemos que en el mismo período el PIB mundial a precios corrientes creció $120 \%$ (a precios constantes sólo $35 \%$ ), y que al fin del decenio el comercio mundial llegó a los 3.6 billones (trillones) de dólares. Esto es, a menos de la mitad del crédito bancario extrafronterizo, que es a su vez una fracción de los movimientos internacionales de capital.

Para América Latina y el Caribe los préstamos externos crecieron mucho menos en ese decenio, apenas un $45 \%$, y se concentraron en los últimos años. Recordemos que durante la "década perdida" los bancos prácticamente sólo prestaron para refinanciar intereses impagos, es decir, para mejorar la presentación de sus propios balances. Tampoco en los últimos años sus préstamos voluntarios han sido significativos, ni por su magnitud absoluta ni en comparación con otros rubros de la cuenta de ingresos de capital.

Sigamos con otro mercado tradicional: la colocación de bonos. Llama la atención el crecimiento de la participación de los países en desarrollo en las emisiones internacionales de bonos: éstas prácticamente se septuplicaron en el último quinquenio, llegando a más de 30000 millones de dólares en 1993. Aun así, representaron apenas el $10 \%$ del total de bonos inter- 
nacionales emitidos ese año en el mundo. Y América Latina, que en 1989 colocó tan sólo 830 millones, superó en 1993 los 20000 millones.

Bastante se ha comentado el desenvolvimiento verdaderamente pasmoso de un segmento del mercado internacional de capitales: el de las transacciones cambiarias o de divisas. Sobre su dimensión se han arrojado cifras que dan vértigo, por su magnitud y sus diferencias: entre cincuenta y cien veces el valor del intercambio mundial de bienes y servicios reales. $\mathrm{Y}$ aun así, en un informe reciente del Fondo (FMI, 1993a) se sostiene que "por cierto, tanto el tamaño del mercado como el número de operadores privados capaces de inyectar sumas muy cuantiosas en los mercados cambiarios son claramente hoy mucho mayores que en el pasado, y ambos probablemente han sido subestimados".

Como botón de muestra, otro segmento del mercado de capitales ilustra bien el ingrediente especulativo que lo caracteriza. Nos referimos a los mercados de productos "derivados" (futuros, opciones, swaps). Las transacciones de derivados muestran un crecimiento explosivo. Según estimaciones presentadas en otro informe del Fondo (FMI, 1993b), ese mercado aumentó de 1.6 billones (trillones) de dólares en 1987 a 8 billones (trillones) en 1991 (tanto como el total del mercado bancario internacional). Así, de representar el 35\% del PIB de los Estados Unidos, pasó a representar más del $140 \%$ de él.

Un ejemplo interesante de la complejidad de estos derivados lo constituyen los contratos a futuro de tasa de interés. En 1987 fueron de 500 millones de dólares denominados en dólares y 141 millones denominados en otras monedas. En 1991 fueron de 1500 millones en dólares y del mismo orden en otras monedas. El aumento de magnitud y el cambio en la composición por monedas son dos datos que han de tomarse en cuenta. Como dice Carlos García Tudero, estos recursos dejaron de cumplir su función inicial de cobertura para desempeñar cada vez más un rol especulativo.

Frente al crecimiento vertiginoso del mercado de derivados financieros los técnicos del Fondo reflejan la preocupación de las autoridades monetarias del mundo desarrollado. En el informe aludido (FMI, 1993b) se lee: "aunque los participantes en los mercados de derivados están expuestos a los mismos tipos de riesgos que en otros mercados financieros -riesgos de crédito, de mercado, de liquidez, legales y políticos- existe la preocupación de que la velocidad a que se han expandido estos mercados y la complejidad de muchos de los instrumentos han aumentado el riesgo de administración". O sea, de desvíos especulatorios de los operadores, desvíos que entre otras cosas han nutrido en los últimos tiempos ficciones noveladas y filmadas. (Y la reciente crisis del tradicional Banco Barings).

Vayamos a otro dato importante sobre la naturaleza y la dimensión contemporáneos de los mercados de capitales. Entre las fuentes más importantes que nutren esos mercados se encuentran, como es sabido, los inversores institucionales. Uno de los principales grupos de esos inversores está constituido por los fondos de pensiones de algunos países desarrollados. En 1988, según un experto del Banco Mundial (Davis, 1993), la inversión neta total de los fondos de pensiones de los Estados Unidos fue de 726000 millones de dólares. Esto representó casi el 50\% del ahorro personal total de ese país y el $35 \%$ de su PIB. En el Reino Unido las cifras correspondiente fueron de $71 \%$ y $47 \%$, respectivamente.

El total de activos invertidos por los fondos de pensiones de los Estados Unidos llegó en el mismo año a la friolera de 16.5 billones (trillones estadounidenses), que representaban el $13.5 \%$ del total de activos personales de ese país. Para entonces sólo el $4 \%$ de ese total estaba colocado en el exterior, aunque hay que tomar en cuenta que en 1980 sólo el $1 \%$ lo estaba. Esto indica una tendencia de los inversores institucionales que puede ser muy importante para los países de la región.

$\mathrm{Si}$ bien el ingrediente especulativo de las inversiones desafía la medición, hay economistas que buscan acercarse a una medida, aunque sea indirecta. Así, Tesar y Werner (1993, p. 20) encontraron que el volumen bruto de flujos accionarios excedía por mucho los flujos netos, y que esta relación era superior en las inversiones externas que en las inversiones internas de los Estados Unidos. Es decir, que en las carteras de los inversores estadounidenses las colocaciones en bolsas del exterior tienen un carácter menos estable - ¿más especulativo? - que las colocadas en su propio país.

Este rasgo debería servir de advertencia sobre la naturaleza de los capitales externos que han contribuido tanto al auge de los mercados emergentes, entre ellos los de varios países latinoamericanos. Y probablemente ayude a explicar su declinación en relación con las alzas de las tasas de interés de corto plazo de los Estados Unidos. El auge de esas corrientes coincidió con la tendencia a la baja de las tasas de interés en ese país; y su estancamiento o declinación con la política de incremento de las tasas de interés de la Reserva Federal.

El comportamiento de los canalizadores de aho- 
rros frente a la inversión interna y externa confirma la propensión del ahorro, salvo circunstancias excepcionales, a colocarse dentro de las fronteras más que a buscar activamente retornos mayores en el exterior. Más aún, esto plantea una paradoja con respecto a la transmisión internacional del ahorro, tema central de la teoría monetaria internacional y cuyo fundamento es que las corrientes internacionales de capital reflejan eficientemente la reasignación de ahorros y la diversificación de carteras entre oportunidades y plazas de distintos riesgos y rentabilidades.

Para evitar simplificaciones que pueden resultar costosas en la realidad, y desde una perspectiva indiscutiblemente neoclásica y convencional, Lucas (1990) nos advierte que las vertientes igualitarias de los modelos más simples de comercio y crecimiento aplican la ley de los rendimientos decrecientes para inferir que el producto marginal del capital es mayor en la economía más pobre. De ahí que la teoría neoclásica convencional -son sus palabaras - postule que si se deja que las fuerzas del mercado operen libremente, la inversión nueva se dirigirá de preferencia hacia los países (o regiones) más pobres, hasta que se igualen los salarios y la rentabilidad del capital.

Hasta aquí Lucas. Las experiencias de América Latina prueban que, o la teoría es falsa, o la libertad de mercados una utopía. Porque la verdad es que los capitales tienden a circular entre los países más ricos, las regiones más ricas y los agentes más ricos, y que sólo se derraman hacia países o regiones más pobres especulativamente $o$ en busca de mayor rentabilidad. En la Argentina hemos tenido en tiempos recientes esta experiencia, interna y externa. Interna con las promociones regionales, externa con la mayor parte de las privatizaciones.

Permítaseme una digresión. Bienvenidos sean los capitales que aporten ahorro externo en condiciones aptas para nuestras necesidades de inversión. Pero tenemos que saber crecer con lo nuestro, como diría Ferrer. Las teorías neoclásicas más recientes sobre crecimiento económico - de Solow a Romer - consideran que la acumulación de capital físico no basta por sí solo para determinar el crecimiento a largo plazo de una economía. Solow, como se sabe, puso el acento sobre un "residuo" no explicado, después de estudiar el crecimiento de la economía estadounidense en un siglo. Romer introdujo el concepto de crecimiento endógeno para dar lugar sobre todo al papel de la acumulación de capital humano (término que horrorizaba al humanista Raúl Prebisch).

Otros economistas muy respetados de la academia septentrional (Barro, Mankiw y Sala-i-Martin, 1992) sostienen que el capital es sólo parcialmente móvil, pues puede financiar la "acumulación de capital físico pero no la acumulación de capital humano". En el mismo trabajo desarrollan un modelo cuya aplicación los lleva a concluir que el principal mensaje de su ensayo es que el impacto cuantitativo de la movilidad [internacional, interregional, interpersonal] del capital es pequeño; si hay ciertos tipos de capital, como el capital humano, que no pueden financiarse con recursos de los mercados mundiales, entonces las economías abiertas convergerán sólo un poco más rápido que las economías cerradas.

Esto es sólo un resultado que de ningún modo puede interpretarse, ni en los autores ni en quien aquí los cita, como una invitación a estrategias de cierre de la economía. Pero quita preocupaciones, desde el más alto nivel teórico, sobre la gravedad de los pecados de protección comercial. Todo a su medida y armoniosamente, por supuesto. Véase si no el caso de Japón y de los nuevos "tigrecitos" asiáticos, o el del "tigrazo" de China.

\section{III}

\section{Fundamentos y consecuencias sistémicas de los movimientos internacionales de capital}

Retornemos al cauce central de estos párrafos. Detengámonos ahora en los fundamentos y consecuencias sistémicas de los movimientos internacionales de capitales y su relación con las asimetrías o brechas de cuenta corriente y de ahorro-inversión, para entrar después a la experiencia reciente de América Latina.
Ya hemos visto que las principales causas del extraordinario crecimiento y acelerada integración global de los mercados de capital internacionales como sistema en la historia reciente de la economía mundial son básicamente: i) la rápida acumulación de excedentes en el primer cuarto de siglo de la posguerra; ii) el 
derrumbe del "muro" de Bretton Woods y el desmantelamiento generalizado de controles de cambio y otros impedimentos a los movimientos de capital entre naciones de economía de mercado; ${ }^{2}$ y iii) los avances tecnológicos en la informática y la computación.

Otro enfoque sistémico del crecimiento de los mercados internacionales de capital se encuentra en la teoría del balance de pagos. Se sabe que hay una identidad macroeconómica contable entre saldos de cuenta corriente y saldos de cuenta de capital. Es decir, que un superávit o déficit en cuenta corriente se salda con un déficit o superávit en la cuenta de capital (con una partida de errores y omisiones para cubrir las discrepancias estadísticas). Otra forma teórica de interpretar esas cuentas de ingresos y egresos externos identifica el saldo de la cuenta corriente como la diferencia entre el ahorro global de una nación y su tasa de inversión.

En un estudio sobre la extensión de la integración financiera global y sus consecuencias (Artis y Bayoumi, 1989), hallamos una observación interesante. Sus autores postulan que una teoría moderna del balance de pagos en mercados de capital integrados extiende a la economía en su conjunto la teoría del consumo y del ahorro de la conducta individual. Se aplica así la teoría sobre la función primaria de los mercados financieros nacionales e internacionales, que es la de canalizar recursos de agentes superavitarios - familias, firmas y gobiernos que gastan menos de lo que perciben, es decir, que ahorran - hacia agentes deficitarios, que gastan más de lo que perciben, o desahorran.

Por supuesto que las consecuencias son muy distintas si la aplicación de los ahorros externos es eficiente o si no lo es: en otras palabras, si se les destina a inversión reproductiva que genere ingresos compensatorios futuros, o a consumo presente. De aquí que haya señales de peligro en buena parte de los países latinoamericanos -y especialmente en Argentina- por la alta propensión al consumo manifestada en dos períodos recientes con gran afluencia de capitales externos, bancarios en la segunda parte de los años setenta, y principalmente no bancarios en los últimos años.

Nosotros tenemos una percepción particular del mundo financiero actual, dentro y a través de las fronteras. Sea cual fuere la validez de la teoría neoclásica del balance de pagos, y de la identidad ahorro-inver-

2 Frenkel (1989) considera que las barreras a los flujos internacionales son lo suficientemente bajas como para decir que en 1989 los mercados financieros están virtualmente integrados del todo entre los grandes países industriales (y entre países más pequeños también). sión globales, en los hechos el mundo vive desde hace un tiempo una creciente y vertiginosa movilidad financiera, con una alta proporción de capitales especulativos, cuyo vínculo con la inversión real puede ser débil o lejano. Se trata de una suerte de ahorro colectivo que gira a alta velocidad, en forma tan satelitaria como las telecomunicaciones que los transportan, prácticamente sin tocar tierra, y cuyos frutos nutren un ahorro que no se canaliza hacia inversiones reproductivas.

Diversos autores han encontrado que las correlaciones entre ahorro e inversión se reducen cuando se sustituye la inversión total por la inversión fija. Abundan los estudios empíricos que muestran que, no obstante la alta movilidad internacional de los capitales, los flujos netos globales de ahorro e inversión siguen siendo marcadamente insulares, es decir, se mantienen dentro de las fronteras de cada país, especialmente en el caso de las naciones más industrializadas. Es la misma conclusión analítica a la que había llegado Tobin (1981).

Veamos ahora algunas de las principales consecuencias sistémicas de los movimientos internacionales de capital, sobre la base de un estudio muy interesante del FMI (Goldstein, Mathieson y Lane, 1991). Aunque su fundamento analítico responde, como es natural, a una visión del mundo desde el Norte, encontramos en ese estudio elementos de juicio que se aplican a la experiencia de América Latina y de la Argentina.

La teoría convencional considera que la integración de los mercados de capital genera ganancias de eficiencia, porque facilita la transmisión del ahorro hacia la inversión más rentable o productiva. Pero en la práctica la transformación estructural de los mercados financieros internacionales, que sin duda facilita la circulación de los ahorros, ha resultado una fuente adicional de incertidumbre, no sólo sobre los vínculos entre los mercados financieros de los países, sino también sobre sus efectos en las políticas monetarias $\mathrm{y}$ fiscales.

Estas consecuencias de la movilidad internacional de capitales se dan de manera distinta según los países tengan posición hegemónica o subordinada en la economía internacional. Así, Estados Unidos ha podido financiar con ahorro externo durante un extenso período - ya van más de diez años- cuantiosos déficit fiscales y de cuenta corriente, absorbiendo shocks endógenos y exógenos. Citemos solamente que entre los shocks endógenos de índole financiera hubo una serie de desórdenes bancarios generalizados como los gene- 
rados por la crisis de la deuda, las carteras incobrables de industrias petroleras y otras y la crisis inmobiliaria de fines de los años ochenta, con su secuela de quiebra difundida de instituciones financieras de ahorro y préstamo. Entre los shocks exógenos prevaleció en los últimos lustros un clima de alta volatilidad de los tipos de cambio y de las tasas de interés.

De otro lado, para tomar un caso que conocemos bien, casi todos los países de América Latina se vieron obligados a realizar ajustes recesivos violentos frente a shocks sistémicos, como los registrados a comienzos de los años ochenta por el alza de las tasas de interés real internacionales y por la caída de los precios de los productos primarios.

En una visión aún más global, puede decirse que los países centrales aprovechan mejor lo que en el trabajo citado se denomina, con llamativo acierto, el bien público internacional de la estabilidad económica mundial. Que por el mismo hecho de ser un bien público internacional plantea la necesidad de coordinar políticas entre los países cuyas políticas internas más afectan el comportamiento de la economía internacional.

Vayamos a otra perturbación sistémica. Las modificaciones fundamentales en las tasas de interés y los tipos de cambio afectan las decisiones de inversión y preferencias de cartera de los operadores más influyentes en los movimientos de los ahorros nacionales a través de las fronteras. Esto genera en las autoridades monetarias centrales, como lo expresan los técnicos del Fondo, una legítima preocupación: si los arreglos institucionales existentes pueden enfrentar con eficiencia el nuevo volumen de transacciones y administrar eficazmente los riesgos creados por crisis de liquidez o de solvencia. Conocimos esas preocupaciones en la extensa renegociación de la deuda. Y vuelven a aflorar en el Norte ante la posibilidad de que los operadores especulativos dominen las transacciones de los mercados de divisas y de títulos, contribuyendo así a aumentar peligrosamente la volatilidad de los precios de una vasta gama de activos financieros.
Otro riesgo sistémico es la posibilidad de que una crisis financiera pueda desencadenarse "por contagio" de temores no muy fundados. El dinero, sobre todo el dinero especulativo, es a la vez audaz y miedoso. La percepción de que la liquidez o la solvencia de un prestatario importante se deteriora puede dar lugar a un efecto de dominó en las finanzas internacionales. Ya ocurrió así con la crisis de la deuda latinoamericana. $\mathrm{Y}$ es una de las interpretaciones de la Gran Crisis de los años treinta, que en el recuerdo quedó como un reguero de pólvora que corrió desde Wall Street hasta casi todos los rincones del mundo.

Finalmente, recojamos una opinión del estudio citado que merece tomarse en cuenta para el análisis de las perspectivas a mediano plazo de las corrientes internacionales de capital. La larga declinación de las tasas de ahorro tanto en países industriales como en países en desarrollo (donde el ahorro neto bajó de $17 \%$ a $10 \%$ del PIB entre 1973 y 1988), así como la demanda creciente de ahorros mundiales (por la recuperación de las economías centrales y de países en desarrollo, la reconversión de las economías del este de Europa, el gran mercado de China y la India, etc.), sugieren que si no aumentan significativamente las tasas de ahorro "una de las características de los años noventa pueden ser las altas tasas de interés", especialmente en instrumentos de largo plazo más ligados a la demanda de inversión. Recordemos las dificultades de la Reserva Federal de los Estados Unidos para hacer bajar las tasas de interés a largo plazo, y la necesidad de recurrir a aumentos importantes en las de corto plazo.

Agreguemos a esto que mientras se mantenga la volatilidad cambiaria internacional, que parece persistir, la prima de riesgo cambiario -que tan bien conocimos los argentinos - es una importante fuente de diferencias de interés real en los mercados financieros. Esto quiere decir que no es prudente subestimar el costo real de los ingresos de capitales en estos y los próximos años, ni el nivel de rentabilidad que es necesario alcanzar para pagarlos o retribuirlos.

\section{IV}

\section{Financiamiento externo de la región}

Pasemos ahora al financiamiento externo de América Latina. Como es sabido, la región ha padecido un problema crónico de estrangulamiento financiero ex- terno, cuyas raíces estructurales fueron expuestas en forma clara y profunda por Raúl Prebisch. Yo creo que el propio Prebisch corregiría parte de su diagnós- 
tico, basado en el comportamiento del comercio y la inversión —es decir, de la economía real —, para agregarle las características o distorsiones de la globalización financiera que hemos tratado de presentar en la páginas anteriores.

A pesar de que algunos países de la región han ido superando su desventajosa inserción en el comercio mundial como exportadores de bienes primarios, el sector externo sigue siendo un flanco expuesto de las economías. A ello han contribuido en los últimos lustros los bruscos altibajos de las corrientes financieras internacionales. Las economías latinoamericanas en general se han movido por lo menos desde mediados de los años setenta no sólo al compás de la relación de precios del intercambio y de la actividad económica mundial, sino también bajo el impacto de la abundancia o escasez de capitales externos.

Antes de ensayar un análisis - siempre preliminar, pues la historia sigue su sorprendente marcha-, refresquemos algunos datos numéricos. Lo haremos desde tres perspectivas: i) la del balance de pagos, su cuenta corriente y su cuenta de capital; ii) la de la transferencia neta de recursos y, finalmente, iii) la del movimiento neto de capitales.

Entre 1976 y 1982 - los años del endeudamiento, primero neto y al final de mera postergación de la crisis- la región tuvo déficit en cuenta corriente elevados y en rápido crecimiento (de más de 11000 millones de dólares en 1976 a más de 40000 millones en 1982). La crisis y el consiguiente ajuste contrajeron rápidamente ese déficit. En 1983 se redujo a un quinto de aquél del año anterior y con altibajos se mantuvo alrededor de ese nivel hasta 1990. Pero ya en 1991 el déficit saltó nuevamente a casi 20000 millones, y a más del doble en 1993.

La contracara de ese movimiento de la cuenta corriente viene en la cuenta de capital, fuertemente positiva hasta 1981 , negativa hasta 1990 , y notablemente positiva desde entonces. Recordemos que en 1976 el ingreso neto de capital fue de 16000 millones de dólares, y que ascendió a 37000 millones en 1981 (aunque ya hay que contabilizar aquí renovaciones de préstamos). Dos años después la cuenta se hizo negativa en casi 24000 millones, y el fenómeno demoró ocho años en revertirse. En 1991 se contabilizó un ingreso neto de 25000 millones, que subió a casi 50000 millones en 1992, y fue ligeramente menor en 1993. Así, en la segunda mitad de los años setenta -por obra y gracia del crédito bancario abundantey nuevamente en el último bienio —esta vez por el financiamiento no bancario- los ingresos en la cuenta de capital superan los déficit de cuenta corriente, y permiten la acumulación de reservas y la expansión del gasto.

Otra forma de apreciar estos cambios lo ofrece el conocido concepto de transferencia neta de recursos, medido como la entrada neta de capitales (capitales de corto y largo plazo, transferencias unilaterales oficiales, y errores y omisiones) menos los pagos de utilidades e intereses. ${ }^{3}$ Para la América Latina en su conjunto esta transferencia fue positiva en los años del endeudamiento genuino: un promedio de 15800 millones de dólares por año entre 1974 y 1981. Pasó a ser fuertemente negativa a partir de 1982. Entre 1982 y 1989 también fue negativa (alrededor de $23000 \mathrm{mi}-$ llones de dólares por año). Ya en 1990 había bajado a un déficit de 9000 millones. Y de ahí en adelante las cifras han sido muy positivas: 5000 millones en 1991, 20000 en 1992 y 15000 en 1993.4

Sigamos ilustrando con números la suerte del sector externo de América Latina en los azarosos veinte años últimos, tan dependientes de los ingresos y salidas de capitales. Nos apoyaremos para ello en un excelente estudio de la CEPAL sobre los flujos financieros internacionales, estudio del cual también sacaremos partido en el análisis (CEPAL, 1994). ${ }^{5}$ Veamos esta vez el movimiento neto de capitales. Entre 1977 y 1981 ingresó a la región un promedio de 30000 millones de dólares anuales, con un máximo de más de 40000 millones en 1981. La cifra descendió abruptamente a la mitad al año siguiente, para promediar poco más de 8000 millones entre 1983 y 1989 . Pero a partir de este último año las entradas - y regresos - crecieron rápidamente de 21 500 millones en 1990 a más de 62000 en 1992.

Como señala el mismo estudio de la CEPAL, en los dos últimos años la transferencia neta de recursos representó respectivamente el $2.7 \%$ y el $1.9 \%$ del producto interno bruto de la región, tras haber exhibido una cifra negativa media de $3.7 \%$ en el período de crisis y ajuste (1983-1989).

La historia reciente nos cuenta que en la segunda mitad de los años setenta la mayoría de los países latinoamericanos no aprovechó la disponibilidad de finan-

\footnotetext{
3 Para el Banco Mundial (1993, p. 25), las transferencias netas totales se calculan restando a los flujos netos totales de recursos los pagos de intereses y las utilidades reinvertidas y remitidas. Los flujos netos totales de recursos excluyen el uso del crédito del FMI. Aquí se utilizan la definición y las estimaciones de la CEPAL.

4 Datos adaptados de CEPAL (1992 y 1993), en dólares constantes de 1987.

5 También aprovechamos el excelente ensayo de Devlin, FfrenchDavis y Griffith-Jones (1994), a cuyo manuscrito tuvimos acceso por cortesía de uno de sus autores.
} 
ciamiento externo para aumentar la tasa global de ahorro y para canalizar ese ahorro hacia inversiones productoras de bienes transables. Si esta nueva oleada de ingreso de capitales tampoco se aprovecha para incentivar el ahorro interno, aumentar la inversión reproductiva y reconvertir la economía para hacerla más competitiva en el ámbito internacional, es probable que a la vuelta de una próxima esquina nos espere otro duro despertar, una nueva resaca de otra borrachera financiera.

No somos pesimistas, ni por temperamento ni por ideología. Seguimos simplemente las enseñanzas de la experiencia reciente y de la definición del ortodoxo Lucas (1990), para quien los flujos de capital son simplemente contratos de préstamo: el país pobre adquiere capital del rico, a cambio de promesas de flujos de bienes en sentido contrario, durante una fase (que puede durar para siempre), en forma de pagos de interés o utilidades repatriadas.

En los años del ajuste los pagos de intereses (efectivamente pagados y devengados) fueron el nudo corredizo del estrangulamiento externo. Deberíamos desde ya asegurarnos de que el uso de los nuevos capitales que ahora se reciben transforme nuestras economías y permita generar excedentes para financiar los futuros pagos de utilidades e intereses, hasta completar el círculo virtuoso del endeudamiento compensador y no caer en otra crisis de ajuste cruento y prolongado.

Porque no todo es ventaja y bonanza por el ingreso de capitales. Ya vimos que ellos suelen tener efectos macroeconómicos no deseados, como la valorización del tipo de cambio real y su efecto sobre la evolución de las importaciones y exportaciones, con un fuerte aumento del déficit comercial. Así ocurrió en los primeros años del endeudamiento, y está volviendo a ocurrir ahora. Cuando un país financia el déficit de comercio o de cuenta corriente con ingresos de capitales externos, está expuesto a que una reducción significativa de esos flujos cause un ataque especulativo sobre su moneda que desencadene una crisis de balance de pagos.

Otro peligro macroeconómico ha sido señalado por autores insospechables de heterodoxia: Cavallo y Cottani. Escribieron ellos, en un análisis que parece acertado: Cuando un país acumula reservas, el gobierno permite que el tipo de cambio se aprecie, con lo cual reduce el impacto fiscal de su propio servicio de la deuda. Esta apreciación también alienta a agentes privados a ofrecer deuda o depósitos denominados en dólares. Si aparecen problemas externos, el gobierno pospone un ajuste del tipo de cambio por su propia exposición cambiaria, así como por la del sector priva- do. Cuando finalmente devalúa, el gobierno debe hacer frente a sus propias pérdidas y a las de los bancos privados nacionales. El resultado es una mayor inflación, nutrida por la expansión monetaria, y menos estabilidad económica (Cavallo y Cottani, 1989).

La historia y la teoría enseñan que las economías que quieren crecer y desarrollarse deben aprovechar los momentos de afluencia de capitales para mejorar su especialización internacional. Esto se aplica en particular a los países en desarrollo, que para crecer deben revertir su desventajosa inserción internacional y las consecuencias de lo que Prebisch llamó la distribución desigual de los frutos del progreso técnico.

Los países que no exportan industria -e industria cada vez más tecnificada y diversificada - no sólo se llevan la peor parte en la distribución de las ganancias del comercio internacional por el conocido fenómeno de la declinación secular de los términos del intercambio, sino que también tropiezan con el estrangulamiento externo periódico de sus economías. De ahí que un elemento fundamental para juzgar las ventajas y desventajas de los factores exógenos y endógenos que atraen capitales abundantes en cortos períodos es la medida en que ellos contribuyen a encarar el verdadero desafío del desarrollo: el de crear un sólido círculo virtuoso que permita aumentar el ahorro, invertirlo con alta productividad económica y social, y mejorar la competitividad externa de las economías nacionales.

Para terminar: la ilusión o velo monetario del financiamiento fácil tuvo un desenlace catastrófico con la crisis de la deuda en los años ochenta. Para que no vuelva a ocurrir algo parecido con los abundantes recursos financieros que la región está recibiendo del exterior en los últimos años y para que ellos hagan una contribución efectiva al desarrollo de los distintos países de la región, tendrán que cumplirse dos condiciones esenciales.

En primer lugar, que se sostenga el nivel de esos recursos el tiempo necesario para no generar problemas prematuros de balance de pagos. En segundo lugar, que su utilización sea socialmente eficiente, es decir, que se efectúe un mayor esfuerzo de ahorro interno destinado a ampliar la riqueza productiva y mejorar la inserción internacional de nuestras economías. La historia contemporánea muestra que ésta es una opción estratégica viable y exitosa. Los países que no la sigan con vigor y tenacidad continuarán, con mayores o menores altibajos, empantanados en la crisis secular del capitalismo periférico analizado en los últimos escritos de Raúl Prebisch. 


\section{Bibliografía}

Aglietta, M., A. Brender y V. Coudert (1990). Globalisation financière. L'aventure obligée, Paris, Economica.

Artis, M. y T. Bayoumi (1989): Saving, Investment, Financial Integration and the Balance of Payments, IMF Working Paper, $\mathrm{N}^{\circ} 102$, Washington, D.C., Fondo Monetario Internacional (FMI).

Banco Mundial (1993): Financial Flows to Developing Countries, Washington, D.C.

Barro, R. J., N. G. Mankiw y X. Sala-i-Martin (1992): Capital Mobility in Neoclassical Models of Growth, NBER Working Paper, N ${ }^{\circ}$ 4206, Cambridge, Mass.

Cavallo, D. y J. Cottani (1989): Reformas financieras y liberalización, Estudios, año XII, No 50, Córdoba, Argentina, Instituto de Estudios Económicos sobre la Realidad Argentina y Latinoamericana (IEERAL).

CEPAL (Comisión Económica para América Latina y el Caribe) (1992): Estudio económico de América Latina y el Caribe 1991, LC/G. 1741/Add. 1-P, vol. I, Santiago de Chile. Publicación de las Naciones Unidas, $\mathrm{N}^{\circ}$ de venta S. 92. II. G. 2.

(1993): Balance preliminar de la economía de América Latina y el Caribe 1993, LC/G. 1794, Santiago de Chile.

(1994): La estabilidad macroeconómica y los flujos financieros internacionales, Politicas para mejorar la inserción en la economía mundial, LC/G. 1800 (SES 25/3), tercera parte, Santiago de Chile.

Cornford, A. (1993): The Role of the Basle Committee on Banking Supervision in the Regulation of International Banking, Discussion Papers, $N^{\circ} 68$, Ginebra, Conferencia de las Naciones Unidas sobre Comercio y Desarrollo (UNCTAD).

Davidson, Paul (1991): What international payment schemes would Keynes have suggested for the twenty-first century?, P.
Davidson y J.A. Kregel (eds.), Economic Problems of the 1990s, Inglaterra, E. Elgar Publishers.

Davis, E. P. (1993): The Structure, Regulation, and Performance of Pension Funds in Nine Industrial Countries, Policy Research Working Paper, $\mathrm{N}^{\circ} 1229$, Washington, D.C., Banco Mundial.

Devlin, R., R. Ffrench-Davis y S. Griffith-Jones (1994): Surges in capital flows and development: An overview of policy issues, Santiago de Chile, mimeo.

FMI (1993a): World Economic Outlook. Interim Assessment, Washington, D.C.

(1993b): Systemic issues in international finance, International Capital Markets, parte II, Washington, D.C.

(1994): Perspectivas de la economía mundial, Washington, D.C., mayo.

Frenkel, J. A. (1989): Quantifying International Capital Mobility in the 1980's, NBER Working Paper, $\mathrm{N}^{\circ} 2856$, Cambridge, Mass.

Goldstein, M., D. J. Mathieson y T. Lane (1991): Determinants and Systemic Consequences of International Capital Flows, Occasional Paper, $\mathbf{N}^{\mathrm{o}}$ 77, Washington, D.C., FMI.

Lucas, R. (1990): Why doesn't capital flow from rich to poor countries?, American Economic Review, vol. 80, No 2, Nashville, Tennessee, American Economic Association, mayo.

Tesar, L. e I. M. Werner (1993): International equity transactions and U.S. portfolio choice, NBER Reporter, Cambridge, Mass., National Bureau of Economic Research, Inc., otoño.

Tobin, J. (1981): Domestic saving and international capital movements, American Economic Review, vol. 71, $\mathrm{N}^{\circ}$ 6, Nashville, Tennessee, American Economic Association. 